\title{
Teaching Competencies and Job Satisfaction among Basic Education Teachers
}

\author{
Abdullah Saif AlTobi ${ }^{1}$, Muhannad Al-Shboul ${ }^{2}$, Adnan Aldoulat ${ }^{2}$, Nabeelah Al-Halalsheh ${ }^{3} \&$ Hadeel Aldoulat $^{3}$ \\ ${ }^{1}$ College of Arts and Humanities, A'Sharqiyah University, Oman \\ ${ }^{2}$ School of Educational Sciences, The University of Jordan, Amman, Jordan \\ ${ }^{3}$ Alumniof School of GraduateStudies, The University of Jordan, Amman, Jordan \\ Correspondence: Adnan Aldoulat, Department of Curriculum and Instruction, School of Educational Sciences, \\ The University of Jordan, Amman, Jordan. E-mail: adnan_doulat@yahoo.com
}

Received: Dec. 9, 2018

Accepted: Dec. 17, 2018 Online Published: January 14, 2019

doi:10.5539/mas.v13n2p140

URL: https://doi.org/10.5539/mas.v13n2p140

\begin{abstract}
This study aimed to identify the teaching competencies and job satisfaction among basic education teachers. To achieve the objectives of the study, two study tools, teaching competencies questionnaire and job satisfaction scale, were applied. The study followed a descriptive methodology; its sample consisted of (65) male and female teachers from public schools at Al-jam'a directorate of education in Amman, for the spring semester of the academic year 2014/2015; the participants were chosen randomly. For the purpose of statistical analysis, means and standard deviations were computed. However, the validity and reliability tests were conducted for the study tools. Thus, Cronbach alpha coefficient were applied to measure the reliability of first tool and second tool of the study, which were $(0.869$ and 0.857$)$ respectively.

The results of the study revealed that the level of the teaching competencies possessed by physical education teachers on the total score was high, and the level of job satisfaction possessioned by physical education teachers on the total score was moderate. The results also showed that there were no statistically significant differences at the level of significance $(\alpha=0.05)$ in the three domains of teaching competencies (planning competencies, implementation competencies, and evaluation competencies).

In the light of the results of the study, the study concluded a number of recommendations including: inclusion the teaching competencies to be met by physical education teachers in preparation and teacher training programs; and pay attention to the moral, economic, and social aspects of physical education teachers.
\end{abstract}

Keywords: teaching competencies, job satisfaction, basic education teachers

\section{Introduction}

Knowledge and scientific growth has doubled in the last few decades of the twenty-first century. This scientific revolution has changed the theoretical aspects to include applied and scientific fields. Education was not isolated from these changes, but contributed to and interacted with them in order to bring about the desired change in the behavior of the learner, and work to find modern concepts consistent with the scientific progress in enriching the skills of those who are educated so that they can positively influence the behavior of learners.

The educational system needs to be revised from time to time in order to improve it by improving its internal competencies by choosing better inputs and better organization with more appropriate experiences. The outputs of this system will be at the level of expectations that the society expects with the educational system. In order to achieve this goal, officials have worked in different ways; they have worked to prepare teachers, so new programs for teacher training based on the basic competencies required for the profession of education should be taken into consideration (Al-Khawaldeh, 1990).

Modern education has sought to take care of the educational structure to become more flexible and responsive to rapid changes and rehabilitation of teachers and students alike and at all levels and stages of education. Therefore, the Ministry of Education has taken care to provide teachers qualified educational and scientific to understand the changes of the age and adaptation to the new role, and this requires teaching competencies and skills to enable the teacher of his specialty and methods of teaching (Abdul Baqi, Farid, Abdul Rida, Laikh, \& Mohammed, 2011). 
Teaching competencies are defined as a set of abilities and associated skills, which the teacher is supposed to have to improve the performance of his/her tasks, which is reflected on the process of learning comprehension as a whole, in terms of the success of the teacher, and ability to transmit information to his/her student through planning and preparation of lessons and other applied daily activities (Marai, 1981).

The teaching competence of physical education teacher is defined as the overall behavior of the teacher of physical education, which includes knowledge, attitudes, experiences and skills during the above-mentioned situation. This behavior is characterized by a high level of performance and accuracy (Mohammad, 2001).

Teaching competencies include:

1. Cognitive competencies: It is a set of information, processes, mental abilities and intellectual skills necessary to perform the individual's tasks in various fields and activities related to these tasks.

2. Emotional competencies: It is the performance of the individual and his/her preparations, trends, values, beliefs and emotional behavior, and these cover many aspects such as the sensitivity of the individual and his/her acceptance of himself and his direction towards the profession.

3. Performance competencies: the competencies shown by the individual and includes psycho-motor skills and materials related to physical and motor training.

4. Productive competencies: It means enriching the individual for the competencies in his work and the programs that focus on productive competencies are prepared to produce an efficient qualification, and the efficiency of the production indicates the success of the specialist in performing his/her work with complete mastery and dedication (Zeitoun, 2004).

\section{Related Work}

Al-Rawahi and Al-Henani (2013) conducted a study aimed at determining the degree of ownership of teaching competencies among teachers of school sports in the Sultanate of Oman and knowledge of statistical differences according to gender, teaching experience and educational region. The results of the study found that the degree of possession of the study sample for teaching competencies ranged from low, moderate and high. The results also showed that there were no statistical differences according to type and educational region. There were statistical differences due to teaching experience.

Abdel Baqi and Akheron (2011) have tried to determine the educational competencies of teachers of physical education for the intermediate stage in the provinces of the Middle Euphrates in Iraq. The study concluded that the basic educational competencies are necessary for the teachers of physical education, and that the field of objectives got the first attention followed by planning, implementation, organization and evaluation.

Al-Khazali and Al-Momani (2010) conducted a study aimed at identifying the extent to which the teachers of the basic basic stage in the private schools of the Ministry of Education in the Irbid Region in Jordan have the educational competencies from their point of view in view of the variables of the academic qualification and years of experience and specialization. The results showed that there are statistically significant differences in the degree of teachers possessing teaching competencies due to the years of teaching experience and for the benefit of the teachers and the experience of more than (6) years.

Job satisfaction is one of the most important factors for the success of a teacher or teacher at work, and one of the most important indicators of the success of the school as an educational institution, where job satisfaction represents the total feelings and positive attitudes of teachers to work in the teaching profession. Therefore, employees in any organization are more relevant, efficient and motivated to accomplish when they are satisfied with their work, especially when the source of this feeling is work rather than material return from the job (Sheikh, 2001).

The subject of job satisfaction has received the attention of many researchers in the field of education, because it has a positive effect in raising morale and achieving psychological compatibility of teachers, high level of production and low level of psychological stress related to school environment (Al-Hawish, 1999; Al-Walidi, 2001)

Job satisfaction is defined as a positive attitude toward the teacher's job, as he/she is satisfied with the various environmental, social, economic and administrative factors related to his/her job (Abu Sheikha, 1997).

The theory of return equity in its interpretation of job satisfaction assumes that the individual tries to obtain the return while doing a job, and is satisfied with the extent to which the return of his/her work is what he believes the return is due to. This confirms the extent of the service provided by the organization to its employees and its impact on good performance; the individual has his/her job especially teachers. It is therefore believed that there is an inverse correlation between the lost return and the actual return on the one hand and job satisfaction on the other 
hand. Where the individual is a balanced process between the process of return and the individual to the institution, if the return of the return of the individual to the institution is more satisfied, and any imbalance in favor of the institution less job satisfaction (Hean \& Garrett, 2001).

Thaibiti and Al-Anzi (2014) found that there were statistically significant differences in the level of job satisfaction of teachers due to the variable of scientific qualification and in favor of the bachelor's and postgraduate qualifications. There were also significant differences in the level of job satisfaction for teachers.

AlZaydat (2009) found through his study that the job satisfaction of the teachers of physical education has shown a good level; and the absence of the impact of gender variables, experience and scientific qualification on the areas of job satisfaction.

In view of the importance of this subject, the current study aimed to identify the degree of having physical education teachers for the teaching competencies necessary to teach physical education and the level of job satisfaction, and their relationship to some variables.

\section{The Problem of the Study and Its Questions}

The teacher's overall possession and the teacher of physical education in particular for teaching competencies and practice and satisfaction with his/her work is an important pillar in the process of development and modernization of effective education, so increasing the effectiveness and adequacy of education depends on the level of teachers working and the level of performance.

The teacher who possesses the teaching competencies is more confident in the procedures and decisions he/she takes to reach his/her students to the desired educational goals successfully and in view of the importance of this subject. This study was conducted to identify the competencies required by teachers, whether public, professional, educational, social or cultural, or the competencies of professional self-development, in an attempt to answer the questions related to the development of educational and professional skills of teachers, as well as what prompted the researchers to conduct this study to determine the degree of possession of teaching competencies that must be available $\mathrm{M}$ at this stage, and get to know the level of job satisfaction for them to help improve the teacher in teaching physical education, for this school stage of a profound impact on the student's personality comprehensive development. The problem of this study is determined by answering the main question: What is the degree of possessing the teaching competencies and the level of job satisfaction amongthe basic stage the physical education teachers from their point of view and their relationship?

The main question of the study is divided into the following questions:

1. What is the level of teaching competencies among the basic stage physical education teachers?

2. What is the level of job satisfaction among the basic stage physical education teachers?

3. Is there a relationship between the level of teaching competencies and the level of job satisfaction among the basic stage physical education teachers?

\subsection{Objectives of the Study}

This study aims at knowing:

1- Level of teaching competencies possessed by basic stage physical education teachers.

2- The level of job satisfaction possessed by basic stage physical education teachers.

\subsection{The Importance of Studying}

The importance of this study lies in the usefulness that will be given to the officials in identifying the level of job satisfaction of the teachers of physical education and the level of their possession of teaching competencies and the relationship between them in the schools of the Ministry of Education. This study also draws on the importance of the results and the usefulness of them. Development of human resources on vocational self-development in general, and in teacher-based training programs based on the competencies required by teachers.

\subsection{Terms of Study and Procedural Definitions}

- Adequate teaching: A set of abilities and associated skills, which the teacher is supposed to possess in order to perform his or her duties, roles and responsibilities (Abdel Baqi \& Akheron, 2011). It is defined as the level to which the teacher obtains the competencies scale prepared for this purpose.

- Job Satisfaction: A term is defined as an inner sense of the individual being satisfied and satisfied as a result of satisfying his/her needs and desires by practicing the job in which he works, which results in a kind of satisfaction and acceptance of the individual for his/her duties and tasks (Al-Khairi, 2008). The 
level to which the physical education teacher obtains is based on the job satisfaction measure prepared for this purpose.

- Teachers of Physical Education: Those who have a certificate in the field of physical education from a male or female university or university and study physical education in the Jordanian public schools.

- Basic stage: This study is intended to include the fourth grade, up to the tenth grade.

\subsection{Study Limits and Determinants}

This study is based on descriptive analytical methodology. This method requires clarifying its spatial, temporal and objective boundaries. The results of this study are determined as follows:

- Spatial boundaries: This study is limited to the public schools of the Al-jam'a directorate of education in Amman.

- Time Limits: The research is limited to the period of time extended during the first semester of the academic year 2014/2015.

- Human Limitations: This study is limited to teachers of physical education for the basic stage (4-10) in the Al-jam'a directorate of education in Amman.

- The results of the study will be determined by the tools used in data collection in terms of their reliability and stability, as well as the study sample, methods of selection and characteristics. Therefore, the generalization of the results depends on the nature of the study tools and their psychometric characteristics of sincerity and consistency.

\section{Methodology}

The researchers used the descriptive analytical approach to suit the current study.

\subsection{Study Population}

The study population consisted of all teachers of physical education for the basic stage in the public schools affiliated to the Al-jam'a directorate of education in Amman, which is (78) teachers, including (35) male teachers and (43) female teachers, in the Fallsemester of the academic year 2014/2015.

\subsection{Study Sample}

The study sample consisted of (65) teachers (30) male teachers and (35) female teachers; after the exclusion of (13) teachers from the study community because of their absence during the application of the study for various reasons.

\subsection{Study Instruments}

In order to answer the questions of the study, measuring tools were prepared to collect the necessary data so as to reveal through them the teaching competencies and the level of job satisfaction among the physical education teachers of the basic stage. Through the preparation of researchers to measure the competencies of teaching and the level of job satisfaction as shown below.

\subsubsection{The First Instrument: Teaching Competencies Scale}

After examining the literature review related to teaching competencies of the teachers of physical education, Arab and foreign studies related to the subject of the study, the researchers prepared a scale of teaching competencies in order to determine the level of possession of teachers of physical education of these competencies, (32) items divided into the following areas: The first domain is the planning which contains (12) paragraphs, where the range of marks for this domain ranged between $(12-60)$. The second domain is the implementation whichcontains (10) paragraphs, where the range of marks for this domain ranged between $(10-50)$. The third domain is the evaluation whichcontains (10) paragraphs, where the range of marks for this domain ranged between (10 - 50) also.

Thus, the scale of the total marks of the scale, which is in its final form (32), (32 - 160). The scale is designed according to the five-point Likert-type scale, which shows the level of availability of teaching competencies in the light of gender variables, teaching experience and scientific qualifications, as shown in Appendix 1, according to the following distribution: very high, high, moderate, low, Grading is given $(1,2,3,4,5)$, respectively.

The researchers used three levels to estimate the level of teaching competencies, Level 1: High if the level valueis within the category of (3.68-5). Level 2: Moderate if the level valueis within the category of (2.34 - 3.67) Level 3: Low if the level valueis within the category of $(1-2.33)$. 
In order to verify the validity of thisinstrument, the scale was presented to a group of experts and different reviewers who are specialized in the following fields: measurement and evaluation, curriculum and instruction, teaching and physical education from several faculty members from the Faculty of Educational Sciences and the Faculty of Physical Education at Jordanian universities. Some of the paragraphs were edited, deleted, or added according to the reviewers' comments. The final version of this tool, teaching competencies scale, composed of (32) paragraphs divided into three domains.

\subsubsection{Stability of the Scale of Teaching Competencies}

The stability of the teaching competencies scale was verified after applying it to the survey sample which included (20) teachers from outside the study sample. The stability coefficient was calculated using the Cronbach's alpha stability coefficient of the total instrument with a stability coefficient (0.869). Cronbach-alpha coefficients for subfields ranged between 0.683 and 0.802 , indicating a high stability of the teaching competencies scale. These values are appropriate for the purposes of the present study. Table (1) shows the values of the Cronbach alpha coefficient for each of the domains of this scale as well as for the total scale.

Table 1. The total Cronbach's alpha Factor and each domain of Teaching CompetenciesScale

\begin{tabular}{clcc}
\hline No. & \multicolumn{1}{c}{ Feild } & Paragraphs no. & Cronbach's alpha Factor \\
\hline 1 & Planning & 12 & .802 \\
2 & Implementation & 10 & .683 \\
3 & Evaluation & 10 & .716 \\
& Overall & 32 & $\mathbf{. 8 6 9}$ \\
\hline
\end{tabular}

The stability coefficients shown in Table 1 above indicate an acceptable level of stability for the purposes of this study.

\subsubsection{The Second Instrument: Job Satisfaction Scale}

After reviewing the theoretical literature and previous studies, the researchers developed a scale to measure and determine the level of job satisfaction of the teachers of physical education according to the sfive-point Likerttype scale. The final version of this tool, job satisfaction scale,composed of (30) paragraphs divided into three domains; according to the following distribution: very low, low, moderate, high, and very high grades were given $(1,2,3,4,5)$, respectively. The scores on this scale ranged between (30-150).

The scale was presented to a group of reviewers and their feedback and suggestions were made. The appropriate comments were made by deleting and modifying a number of paragraphs, and adding some paragraphs. The final form of the scale consisted of (30) paragraphs: (7) negative paragraphs $(3,5,7,10,11,15$, and 19), where their values were reversed when processing data statistically.

Consequently, the researchers used three levels to estimate the level of job satisfaction: Level 1: High if the level valueis within the category of (3.68-5). Level 2: Moderate if the level valueis within the category of (2.34 - 3.67). Level 3: Low if the level valueis withinthe category of(1-2.33).

\subsubsection{Validity of the Scale of Job Satisfaction}

In order to verify the validity of thisinstrument, the scale was presented to a group of experts and different reviewers who are specialized in the following fields: measurement and evaluation, curriculum and instruction, teaching and physical education from several faculty members from the Faculty of Educational Sciences and the Faculty of Physical Education at Jordanian universities. Some of the paragraphs were edited, deleted, or added according to the reviewers' comments. The final version of this tool, teaching competencies scale, composed of (30) paragraphs.

\subsubsection{Stability of the Scale of Job Satisfaction}

The stability of the jobsatisfaction scale was verified after applying it to the survey sample which included (20) teachers from outside the study sample. The stability coefficient was calculated using the Cronbach's alpha stability coefficient of the total instrument with a stability coefficient (0.857); indicating a high stability of the jobsatisfaction scale. This valueis appropriate for the purposes of the present study.

\section{Results of the Study and Discussion}




\subsection{Results Related to the Question One of the Study}

The first question of the study states "What is the level of teaching competencies among the basic stage physical education teachers?" To answer this question, the arithmetical averages and standard deviations were extracted for each paragraph of the teaching competency scale, for each of the three domains and for the scale as a whole. Table 2. illustrates this.

Table 2. Means andStandard Deviations of the Responses of Physical Education Teachers on the Teaching Competencies Scale for each Domain of the Scale Ranking in Descending Order According to the Mean

\begin{tabular}{llllll}
\hline No. & Rank & Domain & Mean & Standard Deviations & Level \\
\hline 1 & 1 & Planning Competencies & 4.39 & 0.44 & High \\
2 & 2 & Implementation Competencies & 4.10 & 0.48 & High \\
3 & 3 & Evaluation Competencies & 4.08 & 0.53 & High \\
& & Overall & $\mathbf{4 . 2 0}$ & $\mathbf{0 . 3 5}$ & High \\
\hline
\end{tabular}

Table 2. shows that the overall level of teachers' acquisition of teaching competencies was generally high, with a mean of (4.20) and a standard deviation of (0.35). It can be noticed that teachers' teaching competencies level wasalso high in the three domains. The mean and standard deviation for the first domain which related to planning competenciesare (4.39) and (0.44) respectively. The mean and standard deviation for the second domain which related to the implementation competenciesare (4.10) and (0.48) respectively. Lastly,the mean and standard deviation for the third domain which related the evaluation competencies are (4.08) and (0.53), respectively. According to Table 2., the results indicate that the level of possession of teachers of physical education for teaching competencies was generally high.

The researchers attributed this result to the awareness of physical education teachers and their sense of the importance of physical education, especially which is related to the policy of the Ministry of Education in this subject through the development of curricula in the recent period. This result can also be attributed to the level of rehabilitation of physical educationteachers in the field of education, as many of the public universities have colleges of physical education and these colleges incorporate many courses in the educational sciences, which reflected positively on the qualification of physical educationteachers. The teaching competencies are necessary for teachers to perform their educational role effectively. This result can also be attributed to the teaching experience of physical education teachers, indicating that they have been subjected to many educational rehabilitation courses, which also reflected positively on their performance.

The results showed that the planning competencies domain ranked number one among the competencies of the physical education teachers because of the interest shown by the teachers in the competencies of this domain,as they belief that planning is the means and the right way to achieve the goals they have draw. The researchers attribute the implementation competencies domain to the second place because there are some obstacles to the implementation plans of teachers such as stadiums and gymnasiums in most public schools, if not all, as well as lack of technological means which are necessary to carry out some activities that may be dangerous or require high skills. Teachers need technological means to illustrate these skills by presenting simulations using technology.

In terms of the evaluation competencies domain, which ranked the last among alldomains of competencies; the researchers may attribute this result to the lack of commitment by physical education teachers towards the types of appropriate evaluation of physical education, which are based on observation and interview and role play, either lack of knowledge of teachers on these evaluation methods or they do not analyze the results of the evaluation and use it in the restructuring of teaching. The results of this study are in line with the findings of the following studies: Al-Rawahi and Al-Hahanii (2013) andAbdul Baqi et al., (2011).

\subsection{Results Related to the Question Two of the Study}

The second question of the study states "What is the level of job satisfaction among the basic stage physical education teachers?" To answer this question, the means and standard deviations were calculated for each paragraph of the job satisfaction scale and the overall score of the instrument; as shown in Table 3.

Table 3. Means andStandard Deviations of the Responses of Physical Education Teachers on the Job Satisfaction Scale Ranking in Descending Order According to the Mean 


\begin{tabular}{|c|c|c|c|c|c|}
\hline No. & Rank & Paragraph & Mean & $\begin{array}{l}\text { Standard } \\
\text { Deviations }\end{array}$ & Level \\
\hline 4 & 1 & My job is no less important than other jobs & 4.37 & 0.55 & High \\
\hline 30 & 2 & I feel comfortable when my students value my efforts & 4.32 & 0.50 & High \\
\hline 29 & 3 & $\begin{array}{l}\text { My job makes me happy with my relationship with my } \\
\text { application }\end{array}$ & 4.26 & 0.59 & High \\
\hline 12 & 4 & $\begin{array}{l}\text { I feel happy about the relationship between me and my } \\
\text { students }\end{array}$ & 4.22 & 0.60 & High \\
\hline 27 & 5 & $\begin{array}{l}\text { My character was characterized during my work at } \\
\text { school }\end{array}$ & 4.22 & 0.54 & High \\
\hline 28 & 6 & $\begin{array}{l}\text { I feel happy and delighted by my colleagues' } \\
\text { appreciation of my work }\end{array}$ & 4.20 & 0.54 & High \\
\hline 24 & 7 & I developed my social relationships through my job & 4.18 & 0.56 & High \\
\hline 25 & 8 & $\begin{array}{l}\text { I love my job as a teacher of sports education because } \\
\text { it is science and art }\end{array}$ & 4.11 & 0.62 & High \\
\hline 22 & 9 & $\begin{array}{l}\text { I love my profession as a teacher of sports education } \\
\text { despite the difficulties I face }\end{array}$ & 4.05 & 0.62 & High \\
\hline 1 & 10 & My job allows me to highlight my abilities and skills & 3.98 & 0.70 & High \\
\hline 2 & 11 & $\begin{array}{l}\text { I am satisfied with the freedom granted to me in } \\
\text { accomplishing my work }\end{array}$ & 3.97 & 0.68 & High \\
\hline 23 & 12 & My work gives me more freedom to work in school & 3.91 & 0.68 & High \\
\hline 21 & 13 & I can make decisions about my work & 3.88 & 0.55 & High \\
\hline 20 & 14 & $\begin{array}{l}\text { My work earns me recognition and respect for my } \\
\text { superiors }\end{array}$ & 3.86 & 0.58 & High \\
\hline 14 & 15 & I am happy for the benefit my work brings to society & 3.80 & 0.92 & High \\
\hline 26 & 16 & My job at school meets my wishes & 3.77 & 0.75 & High \\
\hline 17 & 17 & My work creates opportunities for creativity & 3.75 & 0.77 & High \\
\hline 16 & 18 & $\begin{array}{l}\text { I am happy to appreciate the community for my work } \\
\text { as a teacher of sports education }\end{array}$ & 3.74 & 0.69 & High \\
\hline 18 & 19 & My job achieves my ambition & 3.71 & 0.79 & High \\
\hline 8 & 20 & I feel job security in my job & 3.69 & 0.75 & High \\
\hline 19 & 21 & I do not want to continue my work & 3.25 & 0.95 & Moderate \\
\hline 9 & 22 & $\begin{array}{l}\text { I believe that the policy of incentives and rewards is } \\
\text { appropriate for my work }\end{array}$ & 3.08 & 0.87 & Moderate \\
\hline 15 & 23 & I feel regret for my choice of this profession & 2.92 & 1.16 & Moderate \\
\hline 13 & 24 & $\begin{array}{l}\text { I feel that the Ministry of Education provides the right } \\
\text { conditions }\end{array}$ & 2.85 & 0.75 & Moderate \\
\hline 6 & 25 & The salary I earn is enough to cover the cost of living & 2.75 & 0.81 & Moderate \\
\hline 10 & 26 & I do not see my job as important to society & 2.66 & 0.86 & Moderate \\
\hline 7 & 27 & My job does not allow me to achieve my goals & 2.45 & 0.94 & Moderate \\
\hline 5 & 28 & My bosses do not deal fairly with everyone & 2.17 & 1.19 & Low \\
\hline 11 & 29 & $\begin{array}{l}\text { I am not satisfied with the amount of annual increases } \\
\text { granted to me }\end{array}$ & 1.95 & 0.96 & Low \\
\hline 3 & 30 & $\begin{array}{l}\text { My salary is not commensurate with my experience } \\
\text { Overall }\end{array}$ & $\begin{array}{l}1.88 \\
\mathbf{3 . 5 3}\end{array}$ & $\begin{array}{l}0.91 \\
\mathbf{0 . 2 9}\end{array}$ & $\begin{array}{l}\text { Low } \\
\text { Moderate }\end{array}$ \\
\hline
\end{tabular}

As illustrated in Table 3., the overall job satisfaction of the physical education teachers was at a moderate level with a mean of (3.53) and a standard deviation of (0.29). The highest aspects of job satisfaction among physical education teachers were represented by paragraph (4), which states: "My job is no less important than the rest of the other jobs", with an average of (4.37) and a standard deviation of (0.55) and paragraph (30), which states "I feel comfortable when my students value my efforts"with a mean of (4.32) and a standard deviation $(0.50)$. The lowest aspects of job satisfaction were represented by paragraph (3), which states that "My salary is not commensurate with my experience" with an average of (1.88) and a standard deviation of (0.91); and paragraph (11), which states: "I am not satisfied with the amount of annual increases granted to me" with a mean of (1.95) and a standard deviation (0.96). 
In general, the means for this scale ranged from (1.88 to 4.37) and with standard deviations ranging from (0.91 to 0.55 ). This result may be attributed to teachers' dissatisfaction with their salaries. As indicated above, paragraph (3) has received the lowest mean and low level. As well as the teachers are not satisfied with how the schools principals are treat everyone fairly. Paragraph (5) and paragraph (11) have low levels; hence, the researchers found that the level of job satisfaction of teachers in general affected by the economic and social aspects, which led to a decrease in the level of job satisfaction. This result was consistent with the results of Thaibiti and Al-Anzi's , (2014) study. However, this result contradicts with Khalil and Shurair's (2008) study which indicated that there were no differences in satisfaction with salary in general.

\subsection{Results Related to the Question Three of the Study}

The third question of the study states "Is there a relationship between the level of teaching competencies and the level of job satisfaction among the basic stage physical education teachers?" To answer this question, Pearson correlation coefficients were calculated to examine whether there is any relationship between job satisfaction and each one of the three competencies (planning, implementation, evaluation) and competencies in general; as illustrated in Table 4.

Table 4. Pearson Correlation Coefficients between Job Satisfaction and each one of the three Competencies (Planning, Implementation, Evaluation) and Competencies in General

\begin{tabular}{ccc}
\hline \multicolumn{2}{c}{ Job Satisfaction } & \multirow{2}{*}{ Competencies } \\
Pearson Correlation & Sign. level & Planning \\
0.00 & 0.973 & Implementation \\
0.12 & 0.333 & Evaluation \\
0.37 & 0.002 & Teaching Competencies (Overall) \\
$\mathbf{0 . 2 3}$ & $\mathbf{0 . 0 6 7}$ &
\end{tabular}

As illustrated in Table 4. There is no correlation between job satisfaction, planning competencies, and implementation efficiencies. Whereas, there was a correlation between job satisfaction and the competencies of the evaluation domain. Pearson correlation coefficient for the evaluation domain was $(0.37)$; which is statistically significant $(\alpha=0.05)$. Researchers may attribute this finding to the fact that the competence of the evaluation domain is not imposed on teachers by the school administration or imposing a specific type of evaluation on teachers, which led to teachers' satisfaction of this domain.

\section{Recommendations}

Based of the results, the study recommends that the teaching competencies should be provided to teachers and be included in the programs of preparing and qualifying teachers and training them and taking care of the moral, economic, and social aspects of physical educationteachers. Also, the study suggeststhat conducting additional studies to examine the teaching competencies and job satisfaction of teachers of other educational stages and with different disciplines.

\section{References}

Abdul Baqi, M., Farid, S., Abdul Rida, H., Laikh, K., \& Mohammed, S. (2011). Educational Competencies for Teachers of Physical Education in the Governorates of the Middle Elphurats. Journal of Physical Education Sciences, 4(3), 36-53.

Abu Sheikha, N. (1997). Job Satisfaction of the Security Man in the Arab Security Services. Riyadh: Center for Studies and Research at Naif Arab Academy.

Al-Rawahi, N., \& Al-Hinai, J. (2013). Instructional Competencies of School Sports Teachers in the Sultanate of Oman and their Relation to the Reasons for Choosing a Teaching Profession. Journal of Educational and Psychological Sciences, 14(1), 513-538.

AlZaydat, A. (2009). The Prevailing Leadership Styles among the Principals of the Public Schools in Zarqa Governorate and their Relation to the Job Satisfaction of the Physical Education Teachers (Unpublished master's thesis). Yarmouk University, Irbid, Jordan.

Charity, H. (2008). Job Satisfaction and Motivation for Achievement in a Sample of the Teachers' Instructors in the general education stages in Al-Layth and Qunfudah Governorates (Unpublished master's thesis). Umm Al-Qura University, Makkah, Saudi Arabia. 
Dinham, S., \& Scott, C. (2000). Moving into the Third, Outer Domain of Teacher Satisfaction. Journal of Educational Administration, 38(4), 379-396. https://doi.org/10.1108/09578230010373633

Hean, S., \& Garrett, R. (2001). Sources of Job Satisfaction in Science Secondary School Teachers in Chile. Compare, 31(3), 363-379. https://doi.org/10.1080/03057920120098491

Hoyish, S. (1999). The Relationship between Work Pressure and Job Satisfaction among Workers in Iron and Steel Factories in the Iron Company SABIC (Unpublished master's thesis). Umm Al-Qura University, Makkah, Saudi Arabia.

Khawaldeh, M. (1990). The Perceptions of those Working in the Preparation of Teachers for the Educational Competencies Required for Teachers of Compulsory Stage in Jordan. Irbid: Educational Research and Development Center.

Khazali, K., \& Al-Momani, A. (2010). The Teaching Competencies of the Teachers of the Minimum Basic Stage in the Private Schools in Light of the Variables of Scientific Qualification and Years of Experience and Specialization in Jordan. University of Damascus Journal, 26(3), 552-592.

Koustelios, A. (2001). Personal Characteristics and Job Satisfaction of Greek Teachers. International Journal of Educational Management, 15(7), 354-358. https://doi.org/10.1108/EUM0000000005931

Kovač, M., Sloan, S., \& Starc, G. (2008). Competencies in Physical Education Teaching: Slovenian Teachers' Views and Future Perspectives. European Physical Education Review, 14(3), 299-323. https://doi.org/10.1177/1356336X08095668

Qatami, Y. (2011). Learning and Teaching Strategies Series: Teaching Models. Amman: Dar Wael Publishing and Distribution.

Sheikh, O. (2001). Series of Evaluation Studies for the Educational Development Program. Amman: National Center for Human Resources Development.

Thaibiti, M., \&Al-Anzi, K. (2014). Factors of Job Satisfaction among Teachers in the Province Qurayyat from their Point ofView. International Journal of Specialized Education, 3(6), 99-118.

\section{Copyrights}

Copyright for this article is retained by the author(s), with first publication rights granted to the journal.

This is an open-access article distributed under the terms and conditions of the Creative Commons Attribution license (http://creativecommons.org/licenses/by/4.0/). 